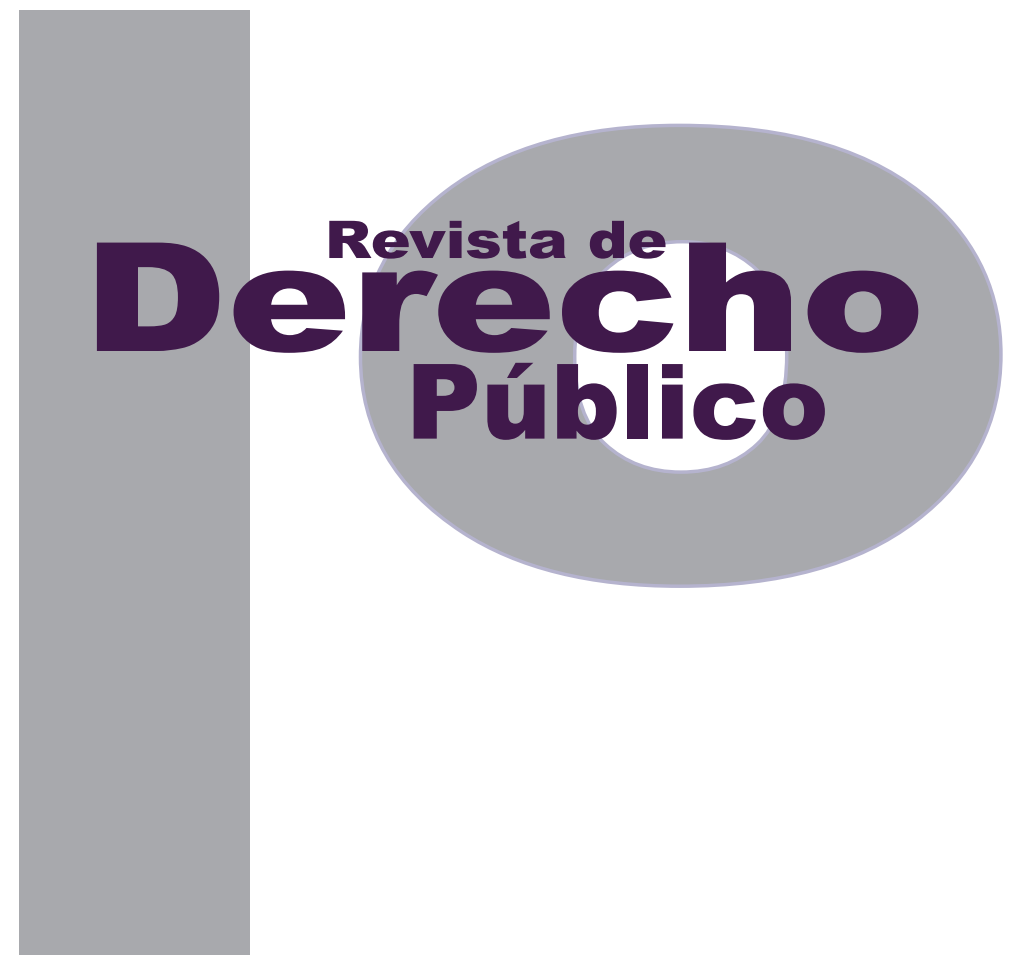

\title{
LAS TECNOLOGÍAS DE LA INFORMACIÓN Y LA COMUNICACIÓN (TIC) EN LOS MODELOS PEDAGÓGICOS DIALOGANTES PARA LA PEDAGOGÍA CONSTITUCIONAL
}

\author{
ERIC LEIVA RAMÍREZ \\ AnA Lucía Muñoz GonzÁLez
}

Universidad de los Andes

Facultad de Derecho

Revista de Derecho Público N. ${ }^{\circ} 32$

Enero - Junio de 2014. ISSN 1909-7778 


\title{
Las tecnologías de la información y la comunicación (TIC) en los modelos pedagógicos dialogantes para la pedagogía constitucional $^{*}$
}

\author{
Eric Leiva Ramírez ${ }^{* *}$ \\ Ana Lucía Muñoz González ${ }^{* *}$
}

\begin{abstract}
RESUMEN
En este trabajo se analiza el papel de las tecnologías de la información y la comunicación (TIC) como herramientas que hacen posible la masificación y la efectividad de la pedagogía constitucional -el conocimiento de los derechos fundamentales y la garantía de estos a través de mecanismos de participación ciudadana-, haciendo uso de un modelo pedagógico dialogante en espacios democráticos no tradicionales como los entornos virtuales de aprendizaje (EVA) o las redes sociales, buscando con ello un mayor nivel de conocimiento y aplicabilidad de los valores que poseen las sociedades democráticas.
\end{abstract}

Palabras clave: tic, democracia, pedagogía constitucional, modelo educativo, proceso educativo.
In this paper is analize the role of Information Technology and Communication (ICT) as tools that enable the mass and effectiveness of constitutional pedagogy -knowledge of fundamental rights and the guarantee of these through citizen participation mechanisms discussed- making use of a dialogue pedagogical model in nontraditional areas such as democratic as the Virtual Learning Spaces (vLs) or social networks, thereby seeking a higher level of knowledge and applicability of the securities held by democratic societies.

KEY WORDS: ICT, democracy, constitutional pedagogy, educative model, educative process.

Cómo citar este artículo: Leiva Ramírez, E. y Muñoz González, A. L. (Junio, 2014). Las tecnologías de la información y la comunicación (TIC) en los modelos pedagógicos dialogantes para la pedagogía constitucional. Revista de Derecho Público, 32.

* Abogado y magíster en Derecho Administrativo de la Universidad Libre de Colombia. Estudiante del Doctorado en Derecho de la Universidad de los Andes. Docente e investigador universitario. Correo: ea.leiva60@uniandes.edu.co

*** Estudiante de la Licenciatura en Educación Básica con énfasis en Humanidades y Lengua Castellana de la Pontificia Universidad Javeriana (Bogotá, D. C.) Correo: amunozg@javeriana.edu.co 


\section{SUMARIO}

Introducción - I. LAS TECNOLOGÍAS DE LA COMUNICACIÓN Y LA INFORMACIÓN EN LOS MODELOS ACTUALES DE ENSEÑANZA - II. LAS TIC Y SU USO EN LAS SOCIEDADES DEMOCRÁTICAS - III. LAS TIC EN LOS PROCESOS DE PEDAGOGÍA CONSTITUCIONAL: EL EMPLEO DE UN MODELO PEDAGÓ-

GICO DIALOGANTE - A. Un modelo pedagógico dialogante para la pedagogía constitucional - IV. CONCLUSIONES - Bibliografía. 
Introducción

Los procesos educativos tienden a ir de la mano de los cambios que afrontan las sociedades en donde estos son aplicados, sin que ello signifique que dicha adaptación sea de forma pacífica. Así, por ejemplo, Sócrates afirmaba que una sociedad basada en la escritura no tiene memoria, mientras que una sociedad que carece de escritura se fundamenta en una fuerte memoria colectiva y no en el olvido, pues la escritura es un símbolo recordatorio, pura apariencia de sabiduría (Poca, 1991, p. 11). ${ }^{1}$ Lo anterior no significa que existiese una visión negativa sobre la escritura, que esta no tuviese importancia o fuese vista como algo contrario a la sabiduría, pues basta con mencionar obras escritas como los Diálogos de Platón y La Política de Aristóteles para demostrar la importancia del texto escrito en la consolidación del saber. Lo que sí explica tal aseveración es el hecho de que para la época de Sócrates, el uso de la oratoria era de vital importancia gracias al claro influjo de los sofistas.

Según Cassany "Escribir es una forma de usar el lenguaje, el lenguaje que a su vez, es una forma de realizar acciones, para conseguir objetivos. Al ser la vida humana tan extremadamente social, una gran parte de nuestras acciones son verbales, de modo que somos más

1 El primer escrito se atribuye a los sumerios de Mesopotamia, es anterior al año 3000 a. C. y fue grabado con caracteres ideográficos. La escritura occidental proviene de la fenicia, que fue adaptada por los griegos y posteriormente por los romanos. La escritura mesopotámica es conocida con el nombre de cuneiforme porque los signos que la componen tienen la forma de una cuña y son diferentes de los jeroglíficos egipcios, los cuales representan generalmente animales y cosas. palabras que hechos o estamos hechos de palabras (1999, p. 25).

Lo anterior permite ir infiriendo que la escritura está ligada directamente al conocimiento y, por ende, ese mismo destino sigue la lectura. La escritura y la lectura fueron concebidas para llenar la necesidad del hombre de comunicarse de forma universal con los demás. Son producto de una fuerte ansiedad del ser humano de transmitir y expresar a todos sus semejantes sus ideas y sentimientos. ${ }^{2}$ La escritura y la lectura son producto de la razón, fueron creadas para servirle a ella, y todo aquello que sea contrario a ese fin sencillamente no está acorde con su esencia.

Sin embargo, y al igual de lo que ocurrió con el paso de la comunicación oral del saber a la escritura, en estos momentos los paradigmas clásicos relacionados con la forma como se llevaba a cabo la expresión del lenguaje escrito, y por ende de la lectura, se han venido transformando de forma sustancial gracias a la entrada de las nuevas tecnologías y su gran acogida por parte de la sociedad actual, como consecuencia de que la información viaja con más facilidad y su acceso goza de menores restricciones, espe-

2 Es evidente que leer y escribir nos conecta con el mundo. A través de estas dos actividades nos relacionamos con los otros, participamos en la realidad social y nos ubicamos en ella de distintas maneras, en definitiva, nos vinculamos continuamente con otros seres humanos. Desde esta perspectiva, la lectura y la escritura son actividades contextualizadas: siempre ocurren en situaciones ligadas al mundo, justo porque su sentido se encuentra a partir de nuestra conexión con él.

Ser lector y escritor se desarrolla simultáneamente sobre dos historias: una historia social en la cual se construye y se consolida una configuración de opciones culturales alrededor de la lengua escrita; y una historia individual de nuestro propio tránsito por la geografía comunicativa (Kalman, 2002, p. 150). 
cialmente en lo que al campo educativo se refie-

re. Así, Said (2009, p. 80) plantea:

El surgimiento de una nueva generación de estudiantes multimedia e hipertextuales, capaces de establecer sus propias trayectorias individuales de construcción de acceso a la información y construcción del conocimiento, así como de alternar roles de lectura y autoría en escenarios virtuales, hacen que los avances TIC en los escenarios de enseñanza estén delineando un nuevo modelo de estudiante, cada vez más activo y constructivo, cada vez más responsable al momento de "acceder a la información, secuenciarla y extraer significados de ella" (Jonassen \& Grablinger, 1990, p. 4). Ello trae consigo la necesidad de replantear una reconfiguración del modelo pedagógico, así como la forma de aproximación que se hace en torno a las tıc y el perfil que deben tener los docentes para sacar el máximo provecho de este nuevo tipo de estudiante, miembro de la generación Bit o generación e.

El presente documento plantea el papel que juegan las tıc en la construcción de un modelo pedagógico dialogante, que contribuya no solo a la comunicación masiva de saberes sino que, como consecuencia de este, aporte a la cimentación de sociedades más democráticas. Para ello se expondrá inicialmente la evolución y significado de las Tıc, así como su aplicación en los actuales modelos educativos. Subsiguientemente, se analizará el papel de las tıc en las sociedades democráticas actuales y, finalmente, se planteará cómo el uso de las tıc es fundamental en la aplicación de un modelo dialogante para la pedagogía constitucional y, por ende, en la construcción de la democracia y la comunidad política.
I. LAS TECNOLOGÍAS DE LA COMUNICACIÓN Y LA INFORMACIÓN EN LOS MODELOS ACTUALES DE ENSEÑANZA

El desarrollo de la tecnología informática está comportando la transformación de la escritura analógica (lápiz, borrador, papel, correo postal, etc.) en digital (teclado, procesadores de textos, correo electrónico, etc.) a un ritmo acelerado:

Este cambio está provocando transformaciones profundas en el uso escrito que están generando nuevas prácticas ("viajar" por Internet en busca de datos, utilizar programas de edición de textos) y productos (e-mails espontáneos y relajados en cuanto a corrección, diálogos y conversaciones anónimas y espontáneas en chats, programas de conversión on line, en tiempo real). Pero, en conjunto, la escritura continúa siendo una forma comunicativa relevante en la comunidad (Cassany, 1999, p. 96).

Para Cifuentes $\left(2013^{3}\right)$, una de las consecuencias de la popularización del acceso a Internet y el uso de los computadores personales en los hogares es el desplazamiento del medio de lectura. Su postura da una perspectiva muy negativa acerca del futuro del texto impreso:

La pantalla, cada vez más amplia y nítida, con una inmensa gama de colores, con el tamaño de las fuentes ajustable a discreción es superior indiscutiblemente a la hoja de papel rígida, monocromática y pesada, reducida a un formato único. Hay otros factores que dejan al libro

3 La página web carece de numeración o paginación. 
en desventaja. El lector de la pantalla no está amarrado ni comprometido con el texto. Si no le gusta puede "scroliarlo"; si tiene un interés específico, puede apoyarse en las herramientas de búsqueda; el texto digital puede venir con ayudas de acceso directo a las referencias o indirecto por medio de pantallas auxiliares donde se desplieguen imágenes, ilustraciones, mapas, videos, relacionados con el texto, todos sin el condicionamiento y la limitación del formato del papel. Es decir, pensar que la lectura digital no arrollará a la lectura de libros de papel es negar los hechos palpables. [Cursivas añadidas].

En el mismo sentido, Goñi plantea que la popularización que posee intrínsecamente el texto digital conlleva una clara prevalencia sobre los documentos impresos, pues el metalenguaje, más que necesario, es útil y benéfico para la sociedad. Una comunidad que no se adecue a la comunicación digital está condenada al rezago, pues las sociedades modernas han venido incorporando cada vez con mayor intensidad el nuevo lenguaje que traen consigo las TIc: ${ }^{4}$

El metalenguaje de la informática y el de la comunicación electrónica son dos áreas de cono-

$4 \quad$ "Cierto es que se pueden producir nuevas formas de analfabetismo no por la incapacidad de leer y escribir, sino por la incapacidad de manejar los nuevos medios tecnológicos o por la imposibilidad de acceder a las nuevas formas de transmisión de lo escrito (la brecha digital puede deberse a la falta de infraestructuras que impidan tener acceso a la red o a un teléfono, no tener acceso al dinero, etc.). No basta la alfabetización, hay que dominar las interfaces y tener acceso a ellas, saber navegar y buscar información en Internet, elaborar página web, aprender a leer y escribir imágenes y sonidos, o conocer las técnicas para elaborar y escribir nuestras propias películas, etc., pero una vez alfabetizados en el nuevo entorno electrónico y digital, la aparición de las nuevas tecnologías facilita ciertas tareas, mejora muchos procesos y ofrece nuevas oportunidades para el acceso universal a la información y la participación en la elaboración y construcción de conocimiento" (Lamarca, 2009). cimiento básicos de la sociedad del futuro, útiles y necesarios en la vida social y profesional de cualquier índole. Su ausencia cualificará a las personas y grupos sociales, generando una nueva discriminación, los llamados "analfatrónicos" del futuro. Serán aquellas personas que estén privadas de acceder a la información y comunicarse a través de estos nuevos lenguajes. Este doble conocimiento, la lectura y escritura digital, debe formar parte del bagaje de los saberes básicos de la población y han de ser incorporados en la vida cotidiana de los ciudadanos, y no solo ser considerados como propios de los especialistas de esta materia, los Ilamados técnicos y programadores (2008, p. 274). [Cursivas añadidas].

Lo anterior significa que con la amplia acogida que han tenido la escritura y la lectura digital, difícilmente habrá campo de interacción social que no se vea influenciado por estas, incluida la educación. Es más, el nivel de adaptación que las instituciones de educación logren de las TIC y los textos digitales es lo que hará la diferencia entre aquellas que brinden educación moderna, de calidad, y las que oferten una educación ortodoxa y no acorde con los requerimientos actuales de la sociedad y el mercado laboral. La escritura y la lectura digital son un fenómeno social imposible de frenar no solo porque son producto de la sociedad misma, sino porque que al estar centradas en el usuario interactivo están expandiéndose en la red, luego de una década glacial de tabúes, prohibiciones, aprendizajes y reinvenciones (Rojano, 2006, p. 105). ${ }^{5}$ Precisamente es por esta característica que se hace necesario
establecer las herramientas adecuadas para respetar los derechos
mínimos que como escritores o lectores poseen todos los usuarios de
los medios tecnológicos digitales. Sobre este aspecto, George Landow 
La inserción de las TIC en los procesos educativos obliga a reflexionar sobre aspectos como la práctica educativa, la profesionalización docente y el desarrollo de estrategias didácticas y de evaluación que hagan un uso adecuado y oportuno de la escritura y la lectura digital. Lo anterior debe llevarse a cabo en un campo de interacción que permita una nueva dinámica dentro y fuera del aula ${ }^{6}$ entre los diferentes actores del proceso educativo:

Las Nuevas Tecnologías de la Información y Comunicación pueden ofrecer alternativas para gestionar e instalar prácticas educativas basadas en los procesos de construcción del conocimiento. Podrá ser entonces propicia la oportunidad para desarrollar otro modelo de audiencia, más activa, crítica y participativa, desde los propios perceptores. Nos planteamos para qué y cómo utilizamos las Nuevas Tecnologías en Educación, qué significados podemos construir con y desde ellas, cómo intervenir en nuestra práctica educativa, desde la reflexión y acción en nuestro rol docente, como profesionales comprometidos de la Educación,

(2009) considera que la escritura digital por gozar de amplio carácter de publicidad y popularidad podría llegar a vulnerar derechos que poseen todas las personas, como son su intimidad y reconocimiento moral a sus obras: "La escritura digital, al consistir en señales electrónicas, nos introduce, querámoslo o no, en una red donde todo se publica constantemente. La intimidad se convierte en una noción cada vez más frágil. El procesamiento de texto muestra un mundo en que lo público y la publicación se han vuelto omnívoros y donde hacer algo público cobra un sentido totalmente nuevo" (p. 172).

Cuando se hace referencia al aula no se está haciendo mención específica del espacio físico en el cual tradicionalmente confluían el docente y sus dicentes. Con las TIC el concepto alcanza una visión distinta: se convierte en aquel tiempo donde convergen todos los actores en pro de retroalimentarse y compartir y adquirir conocimientos. El espacio físico pasa a ser cualquier lugar del planeta donde se pueda llevar a cabo esta interacción. Por ejemplo, el docente puede estar en Tokio y sus estudiantes en Brasilia, Caracas, Buenos Aíres, Bogotá, etc. con nuestro tiempo y nuestra cultura (Tedesco, 2003, p. 11).

Como lo menciona Tedesco, la inmersión en las nuevas tecnologías trae como consecuencia la necesidad de reflexionar sobre el rol que desempeña el docente en tanto comunicadormediador, frente a los procesos de enseñar y aprender con las nuevas tecnologías de la información y la comunicación, además de centrar la atención en las transformaciones de su propia práctica educativa, lo que significa que no se puede seguir enseñando en el siglo XXI como si se estuvieran formando personas para el siglo XX. Ello trae como consecuencia necesaria, que el primer concepto que debe tener presente el educador de hoy es que la lectura y la escritura digital, en vez de alejar al estudiante de estos dos importantes elementos, los acerca cada vez más:

Un dato que hay que considerar es que gran parte de lo que actualmente circula en Internet es información escrita. Por lo tanto, destinada a ser leída. En comparación con la televisión y el video -cuyos contenidos son básicamente imágenes y sonido- el computador y la Internet exigen mucho más habilidad lectora. El computador y la Internet estimulan la lectura mucho más que la televisión. De hecho la interactividad del chat, que tanto gusta a adolescentes y preadolescentes, se sostiene en la rapidez de la lectura y la escritura. La Internet abre la posibilidad de que lo escrito tenga la velocidad y la interactividad de lo hablado. El computador y sus aplicaciones ha significado -a su manerauna revalorización de la escritura y la lectura (Ortiz, 2004). 
El hipertexto ${ }^{7}$ no elimina la escritura y la lectura, como tampoco lo hará con el libro, por el contrario, expande los modos de lectura y escritura, crea nuevos soportes, nuevos formatos de almacenamiento y procesamiento de textos y nuevas funcionalidades, y aporta nuevos modos de expresión, acceso a la información y vías para adquirir y compartir conocimiento (Lamarca, 2009).

La tecnología de los medios se pone al servicio de la didáctica, sus avances hacen prever un cambio en el trabajo docente. La preparación de software educativos, se ha convertido en uno de los escenarios de trabajo de los egresados de las facultades de educación; las salas multimediales resultan ser un laboratorio de primer orden para el trabajo del futuro docente (Gómez, 2002, p. 61).

7 "Gary Marchionini describe el hipertexto como un documento electrónico que aprovecha las ventajas de acceso aleatorio en los ordenadores para superar la estricta linealidad de lectura que imponen los documentos impresos en papel.

Por otra parte, en El libro digital y la www, Luis Codina define el hipertexto como un modelo teórico (una propuesta para organizar la información para que se pueda leer siguiendo relaciones asociativas y no sólo secuencial), una abstracción (el modelo define una manera ideal en la que toda la cultura escrita de la humanidad podría estar al alcance de los usuarios por medio de ordenadores interconectados en una red universal), una clase de programas informáticos (los que sirven para crear documentos digitales y organizarlos para que se puedan leer mediante relaciones asociativas) o una clase de documentos digitales (los documentos creados con esta clase de programas).

Contrariamente al texto impreso, que está paginado de manera lineal, y concebido para ser leído en este orden, el hipertexto se presenta en páginas o pantallas accesibles a partir de cualquier tipo de relaciones pertinentes para el lector. Todos los lectores tienen la libertad de leer un texto normal sobre papel lineal o no lineal, es decir, saltando directamente a los fragmentos pertinentes. El lector del hipertexto conserva esta libertad, sin embargo, contrariamente al libro, la lectura lineal, de pantalla en pantalla, no es sinónimo de estructura o de secuencias. El lector de hipertexto está constantemente llamado a viajar hasta otro nodo debido a un tipo particular de relación y no porque sea la página siguiente. El lector de un hipertexto está, pues, invitado interactivamente a transformarse en autor cada vez que debe enlazar, de manera significativa, los elementos de la información" (Bruguera y Campas, 2007, pp. 45 y 46).
"En la actualidad, frente a los requerimientos de investigación de los docentes, la escritura se hace más visible y, también más atemorizante para algunos. La investigación, y esto es lo que atemoriza, solo comienza a ser nuevo conocimiento, conocimiento social, cuando se escribe y se publican los resultados" (Ortega, 2006, p. 205). Escribir es quizá la actividad lingüística más compleja, porque exige el uso instrumental del resto de destrezas durante el proceso de composición (Cassany, 1999, p. 39), siendo una de ellas el manejo de las nuevas tecnologías. Un docente para quien resulta desconocido el manejo y creación de textos a través del ciberespacio se convierte en un profesional no idóneo para hacerle frente a los requerimientos educativos de la sociedad actual. Infortunadamente, existen profesionales que se desempeñan en el campo educativo, que no vieron venir los avances tecnológicos y su forma de construir y transmitir el conocimiento se ha vuelto arcaica e inentendible.

Por lo anterior, el docente de hoy debe ser consciente de que la lectura y la escritura de los tiempos actuales y futuros se desarrollan especialmente a través del hipertexto, “herramienta didáctica acorde con los nuevos sujetos educativos provenientes de la cultura de la imagen" (Gómez, 2002, p. 58). Por ello, seguir insistiendo en que la lectura y la escritura van desapareciendo con la entrada de los textos digitales, lo único que va a conseguir es ir afianzando "esta falsa creencia [que] entorpece el aprendizaje y el desarrollo de la composición, porque desmotiva al alumnado y presenta el objeto de enseñanza, la escritura, como una antigualla" (Cassany, 1999, p. 96). 


\section{LAS TIC Y SU USO EN LAS SOCIEDADES DEMOCRÁTICAS}

La aparición y evolución de las tic a finales del siglo XX han tenido consecuencias en todos los ámbitos de la vida, suponiendo la apertura de nuevas posibilidades, retos e incertidumbres para la democracia. En efecto, la masificación de la comunicación ha permitido a las sociedades conocer con mayor rapidez las actuaciones de los diferentes actores políticos, permitiendo a su vez ejercer un control sobre estos. ${ }^{8}$ Sin embargo, ello resultaría inútil si se hace de forma irreflexiva, sin debate y carente de argumentos (Uprimny, 2013). Sobre este punto, opina Fuster (2012):

En el debate sobre internet y política pueden identificarse dos enfoques particularmente relevantes. Por un lado, un primer enfoque considera internet como un nuevo canal para los actores políticos y formas de participación existentes. En este enfoque, se considera que internet soluciona problemas actuales del sistema político y refuerza la democracia tal y como se entiende hoy. Por otro lado, un segundo enfoque caracteriza internet como un entorno, una esfera de relaciones sociales, con sus dimensiones económicas, políticas y culturales, las cuales todas juntas determinan qué formas organizativas pueden mantenerse y cuáles deben ser cuestionadas. En este

8 Al respecto es importante mencionar cómo la exitosa campaña de Obama para la presidencia de los Estados Unidos, en 2008, ha permitido replantear algunas posturas críticas sobre el papel de las TIC en las democracias. En efecto, como lo describe Fuster (2012), se ha presentado una revisión teórica junto con una "renovación del interés y confianza en las herramientas en línea para dar nuevo vigor a la política convencional (Gibson, 2009). Se considera que la adopción de la última generación de mecanismos de participación en línea multi interactivos fomenta la voz de los ciudadanos por encima de las élites establecidas (Surowiecki, 2005; Leadbeater, 2008)". segundo enfoque, la cuestión gira en torno a qué sociedad está en formación en este entorno cambiante. Desde esta perspectiva internet no aparece como una "cura" para la democracia, sino como una fuente que, combinada con otros aspectos, podría llegar a transformarla.

Por ello resulta valiosa la inclusión de las tic en los procesos educativos, pues a través de ellas es posible construir sociedades democráticas. Sin embargo, no es suficiente contar con medios tecnológicos, ya que estos sin una orientación enmarcada en la consolidación de espacios de aprendizaje no solo serían negativos a la sociedad, sino, hasta cierto punto, destructivos para ella misma. De ahí que los procesos educativos deban estar acompañados de una política educativa progresiva que permita consolidar una comunicación más directa entre ciudadanía y autoridades públicas, y no simplemente dirigida al uso masivo de los instrumentos tecnológicos, puesto que de emplearse este último enfoque no contribuiría a generar espacios de debate y reflexión política:

La incorporación de las tecnologías de la información y la comunicación en la política ha introducido cambios fundamentales en los sistemas políticos democráticos y ha supuesto nuevas posibilidades de relación entre los ciudadanos y los representantes políticos, permitiendo un cierto reencuentro entre la política y la sociedad. Las tic pueden ayudar técnicamente a la mejora de los canales de información, comunicación, deliberación y participación de los ciudadanos en la toma de decisiones públicas, haciéndolos más inmediatos, sencillos y efectivos. Por otro lado permiten minimizar las limitaciones de tiempo y distancia que 
pueden afectar a la participación política, disminuyen los costes de organización de colectivos y aumentan las oportunidades de comunicación entre personas y de intercambio de contenidos... La comunicación que tenéis en las manos quiere estudiar la relación que se establece entre las TIC - sobre todo Internety la democracia, concretamente los mecanismos de participación ciudadana en la toma de decisiones públicas, acotando el estudio a la participación institucionalizada. A tal efecto, en primer lugar se observa su influencia en la democracia, explorando varias posibilidades en base al ámbito de aplicación de las tic y al grado de innovación democrática permitido (Colombo, 2007, p. 28).

La postura anteriormente expuesta es elemento esencial en la construcción de una democracia, pero no el más determinante en lo que a las TIC se refiere. En efecto, cuando se plantea la construcción de una democracia con el uso de las TIC se está afirmando que por medio de ellas se puede brindar educación a un mayor número de personas, ofreciendo no solo saberes a más ciudadanos, sino aportándoles elementos de juicio para tomar decisiones más conscientes que implican a su vez un mayor compromiso con las posiciones democráticas que adopten. En otros términos, una sociedad que posee un mayor nivel de educación será -democráticamentemás consciente y responsable.

Por lo anterior, podría decirse que las tic juegan una doble función: contribuir a brindar saberes al mayor número de personas posibles (derecho a la educación $)^{9}$ y, con la comunicación de es-

9 El cambio cualitativo y cuantitativo que caracteriza a la economía del saber es la posibilidad de coproducción intensa de conocimientos por tos, aportar elementos de juicio que permitan a la ciudadanía tomar decisiones democráticas de forma más responsable, así como ejercer un control directo sobre los actores políticos mediante mecanismos formales de participación democrática o informales como las redes sociales. ${ }^{10}$ En palabras de Colombo (2007, p. 33):

parte de diversos miembros de una comunidad —entendida como comunidad de intereses y no necesariamente ligada a un espacio físico común-, facilitada por la existencia de un espacio público de intercambio y circulación de saberes y por la codificación y transmisión de nuevos conocimientos fuertemente basados en las TIc. Así "una comunidad con una utilización intensa de conocimientos es una comunidad en la que una parte no desdeñable de sus miembros produce y reproduce el conocimiento cuyos límites se circunscriben a un espacio público (o semipúblico) de circulación de los saberes y en la que la utilización de nuevas tecnologías de información y comunicación ha reducido radicalmente el costo de codificación y distribución del conocimiento" (David y Foray, pp. 7 y 8 ).

Sobre el particular, Colombo (2007, pp. 77-78) menciona algunos casos:

"En este marco de governance electrónica se potencian formas de participación electrónica diversas. En los años noventa encontramos en Estados Unidos y Europa algunas experiencias pioneras. Destaca Minnesota e-Democracy, nacida en 1994 con el objetivo de informar sobre los candidatos y los programas electorales.

Actualmente, se ha ampliado a Estados Unidos y permite a los ciudadanos debatir y opinar sobre temas políticos locales, estatales o federales. En el Reino Unido destaca UK Citizens Online Democracy, creada con el objetivo de ofrecer información y fomentar el debate entre los ciudadanos sobre temas de política general. A nivel local se desarrolla la experiencia Online Democracy in Brent, en la que además de la consulta a la ciudadanía también se ofrecía información y se abría el debate ciudadano.

En los últimos años estas experiencias se han desarrollado enormemente. Siguiendo la variable de alcance territorial destaca Vote for the EU you want, experiencia de ámbito supraestatal impulsada en el 2003 por la Unión Europea con el objetivo de aumentar la participación de los ciudadanos en los debates y la toma de decisiones. Permitía a los ciudadanos votar electrónicamente y emitir sus opiniones en relación con varios temas de interés para la UE.

A nivel autonómico encontramos Democracia.web, impulsada en 1998 por la Fundación Jaume Bofill con el apoyo del Parlamento de Cataluña, con el objetivo de acercar la ciudadanía al Parlamento. Permite a los ciudadanos comunicarse con los diputados y los grupos parlamentarios, seguir las tramitaciones parlamentarias y hacer llegar propuestas de enmienda. Por otro lado destaca la Web de l'Estatut, impulsada en el año 2004 por la Dirección General de Participación Ciudadana, con el objetivo de habilitar un espacio en Internet para el proceso de participación de reforma del Estatuto de Autonomía de Cataluña. Ofrecía información, varias herramientas de participación como foros de discusión, chats y la posibilidad de realizar preguntas y propuestas sobre la nueva ley estatutaria. 
La incorporación de las tic a la democracia ha comportado un gran número de oportunidades y límites para la política en general y para la participación ciudadana en particular... Con respecto a las oportunidades, destaca el hecho de que Internet tiene su principal función en ser un elemento de información y comunicación. ${ }^{11}$ En este sentido, la red tiene la poten-

En el ámbito municipal encontramos Consensus, experiencia que ofrece varias funcionalidades de participación ciudadana a los municipios, con tal de complementar los procesos participativos presenciales. También a nivel local, encontramos Madrid Participa, la consulta ciudadana electrónica con más participantes potenciales (136.227 personas) realizada en España. Tiene lugar en Madrid en junio del 2004 y a través de las TIC y centros presenciales realiza una consulta sobre posibles actuaciones y mejoras en equipamientos que debería promover el Ayuntamiento en el distrito de Centro.

Es preciso señalar que las experiencias mencionadas se encuentran dentro de la estrategia demoelitista, introduciendo cambios en el elitismo democrático sin alterar la lógica de la representación."

11 Fuster menciona algunas posturas conceptuales que relativizan el postulado informativo de las TIC:

"En el debate sobre internet y política pueden identificarse dos enfoques particularmente relevantes. Por un lado, un primer enfoque considera internet como un nuevo canal para los actores políticos y formas de participación existentes. En este enfoque, se considera que internet soluciona problemas actuales del sistema político y refuerza la democracia tal y como se entiende hoy. Por otro lado, un segundo enfoque caracteriza internet como un entorno, una esfera de relaciones sociales, con sus dimensiones económicas, políticas y culturales, las cuales todas juntas determinan qué formas organizativas pueden mantenerse y cuáles deben ser cuestionadas. En este segundo enfoque, la cuestión gira en torno a qué sociedad está en formación en este entorno cambiante. Desde esta perspectiva internet no aparece como una "cura" para la democracia, sino como una fuente que, combinada con otros aspectos, podría llegar a transformarla.

Dentro de la primera perspectiva, según Koopmans y Zimmermann (2003), el debate sobre el efecto potencial de internet en la política y la democracia ha estado desde el principio dominado por el enfrentamiento entre perspectivas escépticas y optimistas (della Porta y Mosca, 2006), utopías y distopías (Silver, 2000), deterministas tecnológicos y deterministas sociales (Vaccari, 2009), teóricos de la movilización y teóricos del refuerzo (Norris, 2002). Los hay quienes proclaman que internet no tiene efectos relevantes en la política y en la democracia. La hipótesis de la normalización predice que la política seguirá siendo "política como siempre», y que las relaciones de poder no se verán cuestionadas por los usos de internet (Mosca, 2007). Otros estudios más recientes se sitúan en posturas más intermedias. Para Bimber (2003), los cambios asociados a los usos de internet pueden crear ventajas para ciertas formas de organización y estructura, y desventajas para otras, que lleven a la adaptación y al cambio en el mundo de las organizaciones e intermediarios políticos. El uso de internet podría tanto fortalecer como debilitar la democracia. cialidad de aumentar la información de los ciudadanos sobre cuestiones políticas, promover la educación democrática de la ciudadanía, permitir la comunicación entre los ciudadanos y sus representantes y aumentar su interés en la política. En relación con la participación ciudadana, permite una distribución más eficiente de la información y la documentación política relevante para los procesos participativos permitiendo una participación más informada. En segundo lugar, permite superar las distancias existentes entre ciudadanos y políticos, propias de las democracias representativas, mediante una comunicación bidireccional e interactiva que posibilita la publicitación de intereses, valores y opiniones de ciudadanos hacia otros ciudadanos y hacia las instituciones. ${ }^{12}$

El enfoque de efectos se caracteriza sobre todo por considerar los cambios como complementarios a las instituciones políticas actuales en las democracias representativas. Pueden diferenciarse dos áreas principales de aplicabilidad en el seno de la perspectiva de efectos: el uso de internet para reforzar componentes clave del proceso político (como el voto y las campañas electorales) (Trechsel, 2007) y el uso de nuevas tecnologías de la información y la comunicación (TIC) para mejorar la administración pública y hacer más accesible la política profesional. Es decir, el uso de tic para mejorar la calidad de los servicios de una administración, comenzando con una mayor accesibilidad a la información y la puesta en marcha de gestión en línea en un sentido consumista, según las pautas de las propuestas realizadas por la Escuela de la Nueva Gestión Pública (New Public Management School) desde la década de 1980 (Hughes, 2003). Las TIC se usan también con el propósito de acercar al ciudadano a las élites políticas, para facilitar el conocimiento y el contacto con los parlamentarios y/o actores públicos (Subirats, 2002). No obstante, algunos autores señalan de qué modo las TIC cuestionan los principios fundamentales de la nueva gestión pública” (Dunleavy et al., 2005).

En relación a este aspecto, menciona Mochi (2001):

"No ignoraremos para desarrollar esta línea de investigación estudios ya hechos sobre estas experiencias como son:

Existen algunos gobiernos locales que ya han realizado esfuerzos importantes para la implementación de páginas web que permiten el acceso de la ciudadanía a la información y facilita a su vez una herramienta de comunicación con los funcionarios representantes políticos electos a través del correo electrónico: es el caso de la ciudad de Austin (Texas) en EE. UU.

La ciudad de Buenos Aires, (Proyecto Consejo Deliberante) en Argentina, los Centros de Gestión y Participación del gobierno de la ciudad de Buenos Aires, en Argentina (CGP). 


\section{LAS TIC EN LOS PROCESOS DE PEDAGOGÍA CONSTITUCIONAL: EL EMPLEO DE UN MODELO PEDAGÓGICO DIALOGANTE}

La Carta Fundamental no es solo para juristas o para iniciados en el conocimiento del derecho constitucional, sino para todos los colombianos y demás personas que habitan el territorio nacional, quienes a su vez deben conocerla, interiorizarla y vivificarla (De Antonio Gómez, 2001, p.. 11). En otras palabras, sumarle su acción, su voluntad y convertir en realidad sus postulados.

Y es que la pedagogía constitucional no se logrará si ella, a su vez, no genera debate, polémica y una crítica implacable referida, claro está, al contenido, no al autor que verá satisfechas sus intenciones si logra simplemente contribuir a la tarea propuesta por el artículo 41 de la Carta Política. "La Constitución debe (poder) ser autocrítica respecto de sus propios fines educativos" (Häberle, 2003, p. 190).

Otros niveles son el rol de las organizaciones de la sociedad civil en la implementación de telecentros que han permitido un uso público de internet así como su enseñanza de utilización por parte de la ciudadanía. Muy importante en este aspecto es la experiencia de Perú.

En Senegal, la liberación de la normativa en materia de telecomunicaciones ha dado lugar a la proliferación de "telecentros", que ofrecen a los ciudadanos acceso a las telecomunicaciones brindado una cantidad enorme de servicios y creando miles de puestos de trabajo.

En Sudáfrica, también el crecimiento de este tipo de centros permitió alcanzar tasas de acceso a los servicios públicos, sin precedentes, así como brindar una información esencial sobre asistencia sanitaria, educación y otros servicios sociales.

Si bien ya existe un vínculo estrecho entre nuevas tecnologías y democracia, todavía está todo por desarrollarse. Por el momento darle a esta posibilidad el nombre de "democracia electrónica", es pensar en la democracia ateniense, donde una pequeña élite tiene acceso a esta extraordinaria forma de información y participación política."
El mandato constitucional exige no tanto la transmisión de conocimientos jurídicos-teóricos; esto es cosa del "gremio" de los juristas. Se trata más bien de comunicar la Constitución como marco y afirmación de los ideales de la educación: "La Carta Política es texto escolar y docente. Su realidad comienza en los salones de clase: ¡la escuela de la Constitución es la escuela! Lo que esta logre beneficia a la cultura constitucional" (Häberle, 2003, p. 190).

Esta vía pedagógica hacia una Constitución vivida no puede ser sobreestimada en su relevancia jurídica mediata y su eficacia a largo plazo. La escuela y la universidad, las escuelas profesionales y la enseñanza para los adultos forman a los intérpretes constitucionales en sentido amplio, pues en la medida en que estos adquieran conciencia de sí, pueden convertirse en intérpretes constitucionales activos. La relación entre los planes de estudio y la Constitución se hace lo más estrecha posible; en sentido amplio se trata de "clases de Constitución". ${ }^{13}$

La pedagogía constitucional es necesaria para lograr una sociedad democrática, pluralista y humanista (Corte Constitucional, sentencia T-179 de 2000), por lo que en un Estado social de derecho adquiere enorme dimensión el postulado establecido en el artículo 67 de la actual Constitución. Al respecto sostiene la Corte Constitucional:

13 El artículo 41 de la Carta Política establece: "En todas las instituciones de educación, oficiales o privadas, serán obligatorios el estudio de la Constitución y la instrucción cívica. Así mismo se fomentarán prácticas democráticas para el aprendizaje de los principios y valores de la participación ciudadana. El Estado divulgará la Constitución.” 
La educación formará al colombiano en el respeto a los derechos humanos, a la paz y la democracia.

Esto se une indisolublemente a la necesaria promoción de los derechos humanos, para que la protección a estos no se quede escrita en las normas. Karel Kasak, en una publicación de la Unesco ("Las dimensiones internacionales de los derechos humanos”, volumen 2, pág. 310) hace esta cruda advertencia:

... es evidente que la promoción es el primero e imprescindible estadio que lleve a la protección: si no fuera así, el único resultado de la promoción serían las 'leyes caídas del cielo' bien conocidas en América del Sur...

La pedagogía constitucional no es un castigo, es una obligación darla y recibirla... En otras palabras: no es sólo la norma la que garantiza la protección a los derechos humanos, pues puede haber numerosas leyes que no se cumplan, lo importante es que la protección sea efectiva. Si en el ejercicio de esa protección se impone un cambio de naturaleza para darle también gran realce a la promoción, es permitido para el juzgador que tramita un amparo tomar decisiones que impulsen la promoción de los derechos humanos, buscándose que no sean estériles las normas que los protegen (sentencia T-227 de 1997). (Cursivas añadidas).

La Constitución no impone un modelo específico y acabado de educación. Dentro del sistema mixto -público y privado- del servicio educativo, le cabe cumplir un destacado papel al pluralismo. El pluralismo y la libertad educativa deben, sin embargo, como condición esencial de fondo, respetar y promover al máximo dos valo- res fundamentales que se erigen en el objetivo del proceso educativo: la democracia y el libre, pleno y armónico desarrollo de la personalidad humana. Así lo ha dictaminado la Corte Constitucional en la sentencia T-337 de 1997:

En efecto, en todas las instituciones de educación, oficiales o privadas, se fomentarán prácticas democráticas para el aprendizaje de los principios y valores de la participación ciudadana (C. P., art. 41). Una idea de democracia militante recorre la Constitución y, conforme a ella, en la escuela, los niños, futuros ciudadanos, han de comenzar a experimentarla como una de sus vivencias más próximas y formadoras. La democracia, como diálogo social y búsqueda cooperativa de la verdad, requiere que las personas, desde los bancos escolares, sean conscientes de sus derechos y deberes y tengan oportunidades de ejercitarlos activa y responsablemente mediante el trabajo en equipo, el respeto a los otros y el ejercicio constante de la solidaridad y la tolerancia. Los conflictos no están ausentes en las escuelas y en sus aulas. Lo grave es que no puedan ser reconocidos y que se desestime la ocasión para fomentar en el cuerpo estudiantil, de acuerdo con su nivel de madurez y de conocimientos, la práctica democrática que sea del caso inculcar y sustentar. Si el proyecto educativo quiere en verdad convertirse en simiente de la sociedad abierta, deberá inducirse a los estudiantes - como sujetos dotados de racionalidad y de espíritu constructivo-, a que participen decididamente en la comprensión y resolución de los problemas y conflictos que a menudo surgen en el ámbito escolar y que les conciernen. (Cursivas añadidas).

Es aquí en donde las Tıc juegan un papel importante en los procesos de pedagogía constitucio- 
nal, pues la promoción de los valores democráticos, inclusive en contextos virtuales, garantiza "el reconocimiento de la necesaria igualdad de oportunidades enmarcadas en la Sociedad de la Información de la que hacemos parte" (Said, 2009, p. 80).

\section{A. Un modelo pedagógico dialogante para la pedagogía constitucional}

Para Ortiz (2009, p. 25) un modelo pedagógico es la "construcción teórica formal que fundamentada [de manera] científica e ideológica [permite] interpretar, diseñar y ajustar la realidad pedagógica respondiendo a una necesidad histórica concreta". Es por esta razón que los patrones pedagógicos deben ser acordes con las transformaciones sociales que afrontan las comunidades que interactúan en los procesos de aprendizaje. De esta forma, resulta indispensable pensar en un modelo pedagógico que atienda dos factores: la gran demanda de parte de la ciudadanía por una eficaz garantía de sus derechos fundamentales y el ejercicio de sus derechos políticos, y la rápida circulación de información que permiten los avances tecnológicos de la sociedad contemporánea.

Ahora bien, pensar en un modelo pedagógico acorde con los dos factores mencionados implica que este permita una interacción en igualdad de derechos entre los actores del proceso educativo, lo que de plano lleva a dejar de lado los modelos clásicos como el conductista, que busca resaltar el papel del docente como detentador del conocimiento y ubicar al estudiante dentro de un contexto de carencia de saber -el térmi- no alumno es bastante útil para este modelo-, que debe atender a lo que el profesor - porque profesa en este modelo- dictamina -porque solo es su voz la que actúa- ${ }^{14}$ Un modelo pedagógico que acepte las diferencias, el respeto de las ideas ajenas (más cuando estas no son las adoptadas por la mayoría de los miembros dentro del proceso educativo). En efecto y de acuerdo con lo planteado por Said (2009, p. 81):

El paso del modelo pedagógico literario al hipermedia trae consigo la adaptación de los contextos de enseñanza hacia contextos de aprendizaje en los que los estudiantes participan, activamente, en la construcción del pensamiento no lineal, desde los escenarios virtuales de acceso a la información y conocimiento dispuestos en la actualidad, así como a través de la inclusión de hipertextos en los contenidos y en la construcción de formas de comunicación asincrónicas.

14 Para Trujillo (2008, p. 136): "Este modelo pedagógico, fruto de la racionalidad instrumental, de la "racionalización y planeación económica de los recursos en la fase superior del capitalismo" (Flórez, 1997,167), sostiene que la conducta de los estudiantes puede ser moldeada según las necesidades de los procesos productivos técnicos. Su método puede definirse en función de la consecución de objetivos previamente definidos en términos operacionales, por medio del reforzamiento de aquellas conductas que más se aproximen al comportamiento esperado. En este esquema el conocimiento se define como conducta observable y los contenidos del proceso educativo tienen que ver con destrezas y habilidades propias de los procesos técnicos.

La relación P-A que supone la meticulosa programación del proceso de enseñanza-aprendizaje, no puede ser descrita solamente como vertical y autoritaria, sino que podría llamarse incluso "dictatorial", en la medida en que el alumno no sólo no tiene la menor posibilidad de participar en la formulación de los planes de enseñanza, sino que tampoco menos puede discutirlos. La idea de desarrollo como un proceso cuantitativo de acumulación de aprendizajes, hace que para este modelo aprendizaje y desarrollo sean sinónimos, razón por la cual se concibe la evolución como un continuo, carente de crisis o conflictos, de etapas o fases. Así, el profesor debe cumplir su papel de operario que ejecuta las técnicas prediseñadas por quienes definieron las instrucciones y los objetivos. Este papel es moralmente aséptico pues, además, en las metas se percibe un marcado relativismo moral" [Cursivas añadidas]. 
Por esta razón, y como lo plantea De Zubiría (2006, p. 194) es importante darle paso a "un modelo dialogante e interestructurante (Not, 1983), que reconociendo el papel activo del estudiante en el aprehendizaje, reconozca el rol esencial y determinante de los mediadores en este proceso; un modelo que garantice una síntesis dialéctica". Así:

Hay que reconocer que el conocimiento se construye por fuera de la escuela, pero que es reconstruido de manera activa e interestructurada a partir del diálogo pedagógico entre el estudiante, el saber y el docente y que, para que ello se presente, es condición indispensable contar con la mediación adecuada de un maestro, que favorezca de manera intencionada, mediada y trascendente el desarrollo integral del estudiante. Un modelo que concluya que la finalidad de la educación no puede estar centrada en el aprendizaje, como desde hace siglos ha creído la escuela, sino en el desarrollo.

Hoy en día, un modelo pedagógico dialogante debe reconocer las diversas dimensiones humanas y la obligación que tenemos escuelas $y$ docentes de desarrollar cada una de ellas. Como educadores, somos responsables del desarrollo de la dimensión cognitiva de nuestros estudiantes; pero tenemos iguales responsabilidades en la formación de un individuo ético que se indigne ante los atropellos, se sensibilice socialmente y se sienta responsable de su proyecto de vida individual y social (De Zubiría, 2006, pp. 134 y 135).

Un modelo pedagógico dialogante para la pedagogía constitucional debe partir del hecho que aunque todos los actores son seres sociales $-\mathrm{y}$ políticos-, un número considerable de estos no tiene claros sus derechos y deberes como integrantes del Estado colombiano, por lo que resulta indispensable diagnosticar "el nivel de desarrollo de los estudiantes y en especial por detectar sus debilidades y fortalezas, dado que hasta ahora la escuela ha estado centrada exclusivamente en ubicar las debilidades de los niños y jóvenes [mayores de edad y ciudadanos ${ }^{15}$ ]" (De Zubiría, 2006, p. 218). El identificar las cualidades del estudiante -así como sus competencias ciudadanas- para apoyarlo, orientarlo y desarrollarlo, "es tan importante como ubicar las debilidades. Hacer que la fortaleza de hoy se consolide mañana, por su propio beneficio y por el beneficio colectivo y social" (De Zubiría, 2006, p. 218).

De la misma forma, en modelo pedagógico dialogante resulta ser el más apropiado para la pedagogía no solo porque existe mayor interacción entre los actores, sino porque al mismo tiempo permite la comunicación y la praxis de los valores democráticos. Por ello, la participación y el diálogo son las principales herramientas para el aprendizaje de los valores democráticos.

Una participación, eso sí, que promueva el debate de ideas con sólidas argumentaciones y no con meras opiniones. Una escuela del diálogo que provoque preguntas; abierta al respeto crítico y activo y no a la mera tolerancia pasiva; sensible tanto a la libertad como a la igualdad,

15 No son sinónimos la mayoría de edad y la condición de ciudadano. En efecto, mayor de edad en Colombia es aquel que ha cumplido los 18 años, mientras que el ciudadano es aquel que ha obtenido su cédula de ciudadanía y, por ende, puede ejercer sus derechos políticos como el de elegir y ser elegido a cargos de elección popular. El que sea un requisito para obtener la ciudadanía ser mayor de edad, esta no opera ipso facto, es necesario solicitarla ante la Registraduría Nacional del Estado Civil. 
un binomio inseparable; que fomente la colaboración y la autonomía; y que se convierta en un espacio permanente de opinión refrendada con argumentos, no en una simple "opinionitis" (Carbonell, 2005, p. 26).

Ahora bien, un modelo pedagógico dialogante para la pedagogía constitucional debe tener presente dos elementos: la interculturalidad de los actores como valor democrático y el uso de las Tic como espacio de interacción en democracia. La interculturalidad es una característica de una sociedad con tanta diversidad como la colombiana. Por lo anterior, para brindar una educación en la interculturalidad se proponen los siguientes parámetros tanto a nivel de contenidos temáticos como en el diseño de las estrategias pedagógicas a emplear:

- Como perspectiva inclusiva, es necesario que interactúen todos los actores y no solo las minorías étnicas.

- Resaltar la diversidad como un valor y no como una deficiencia o elemento a eliminar.

- Reformar la escuela ${ }^{16}$ para conseguir una educación de calidad para todos.

Ahora bien, para desarrollar este marco es necesario buscar la realización de los siguientes objetivos, teniendo presente el uso de las TIC y la flexibilidad, dependiendo de los espacios geográficos, el acceso de los actores a la tecnología y los cambios que vaya teniendo la sociedad:
- Incentivar la equidad educativa, es decir, una educación en igualdad de oportunidades para que todos los actores ${ }^{17}$ (docentes, administrativos, estudiantes y padres de familia) logren desarrollar al máximo su potencial, sin pretender obtener iguales resultados, entendiendo que las diferencias entre ellos no se deban a factores sociales, culturales o económicos.

- Superar el racismo, la discriminación y la exclusión. Para ello, es necesario desnaturalizar la situación de exclusión que afrontan algunas personas y grupos en la sociedad colombiana, promoviendo el cuestionamiento y la comprensión de las causas que contribuyen a que se produzcan situaciones de injusticia y de privación de derechos fundamentales, es decir, hacer visible lo que la mirada unificadora pretende ocultar.

- Favorecer la comunicación y las competencias interculturales. Los actores competentes interculturalmente serán aquellos que tengan la habilidad de interactuar con los demás aceptando otras perspectivas y percepciones del mundo, de mediar entre diferentes perspectivas y de ser conscientes de sus propias valoraciones sobre la diversidad. La competencia intercultural se compondría de conocimientos, habilidades y actitudes, complementados por los valores que cada uno tiene por su pertenencia a una sociedad y a unos grupos sociales determinados. Las actitudes (apertura, voluntad de flexibilizar las propias creencias y comportamientos, empatía, entre otros) constituirían la base de esta competencia.
16 Entiéndase escuela no como el espacio físico, sino como el espacio social donde se construye el conocimiento. Por ello, se incluye tanto la formación básica (primaria y secundaria), como la media vocacional y la educación superior (técnica, tecnológica, profesional y postgradual).
17 Para este trabajo la categoría de actores se encuentra conformada por aquellas personas que desempeñen cualquiera de estos roles: docentes, administrativos, estudiantes y padres de familia. 
- Apoyar el cambio social según principios de justicia social. La meta de la educación para la interculturalidad es transformar la sociedad en un espacio más justo y democrático en donde la escuela juega un papel fundamental en el cambio social y educativo, pues es ahí donde los actores pueden interactuar como seres culturales. Las instituciones educativas se encuentran en una posición favorecida para incentivar la transformación social, de modo que en ella es posible superar las desigualdades (racismo personal e institucional, etnocentrismo, inequitativa distribución de recursos y de relaciones de poder, etc.), sin que se presenten agresiones entre los actores. Para ello es necesario que la escuela transforme su orientación hacia la valoración y aceptación de la diversidad cultural como un elemento positivo para todas las personas que en ella interactúan. De igual manera, es necesaria la formación de profesores para la interculturalidad, que apliquen metodologías en el aula y en el clima escolar que tiendan al intercambio de los valores culturales que posean todos los actores. Esto se complementa con la extensión de la propuesta educativa a todos los ámbitos sociales y no solo al educativo.

Estas estrategias deben aplicarse desde los primeros momentos en que el niño o niña empieza a interactuar con los demás integrantes de la sociedad, siendo la educación prescolar ${ }^{18}$ la que generalmente (no siempre ${ }^{19}$ ) permite ese primer acercamiento desde una óptica educativa:

18 "En el nivel preescolar, la expresión de la propia identidad es un paso necesario para la comprensión de la identidad del otro" (Schmelkes, s. f., p. 8).

En la actualidad, la escuela no es el único espacio de interacción a nivel educativo. Por ejemplo, las academias de baile, artes marciales, clases personalizadas, entre otros, se vuelven campos en los cuales es posible interactuar y aplicar la educación para la interculturalidad.
El diálogo con otras identidades puede y debe perseguirse tanto de manera directa - con las diferencias individuales presentes en cada aula- como de manera indirecta, conociendo acerca de otras identidades. Es esencial trabajar el reconocimiento del otro como distinto, lo que se obtiene en este nivel mediante el trabajo sistemático con hábitos de respeto hacia los compañeros, haciendo conciencia de las características particulares de cada uno de ellos (Schmelkes, s. f., pp. 8-9).

Lo anterior contribuye no solo a mejorar la calidad académica (lo que preocupa a los gobiernos de economías en progreso como la colombiana), sino a objetivar la propia identidad. Al mismo tiempo, "permite aprender a escuchar lo ajeno, a respetarlo y a apreciarlo. Son hábitos que se traducen en habilidades y valores. Se traducen en la curiosidad por conocer lo diferente y por valorar la diversidad, incluida la diversidad cultural" (Schmelkes, s. f., p. 9). De aquí la necesidad de que la incorporación de las TIC en la educación tenga en cuenta la realidad cultural de los estudiantes, respete su diversidad y, aún más, promueva su identidad cultural. En la realidad intercultural colombiana, "la reflexión sobre cómo las TIc pueden contribuir al respeto, la defensa y el conocimiento mutuo de las diferentes culturas supone una exigencia ineludible, pero altamente complicada, toda vez que la cultura occidental [pretende] ser absolutamente hegemónica en este campo" (Marchesi y Díaz, 2009).

En lo que concierne al uso de las TIC como espacio de interacción en democracia y, por ende, en la comunicación y práctica de la pedagogía 
constitucional, vale la pena citar lo que sobre este aspecto anota Díaz (2012, p. 160):

Existe un amplio acuerdo sobre la capacidad de las nuevas tecnologías para "romper" las barreras espaciales y temporales, dotando de un nuevo significado a los conceptos de espacio y tiempo, y posibilitando que el aprendizaje se produzca en cualquier lugar y momento... Esto pone el acento en la necesidad de llevar a cabo un cambio de escenario que suponga desplazar el foco de atención y estudio de la escuela a la sociedad. Como señaló Durkheim (2000), la educación es principalmente un proceso de socialización, de adquisición de habilidades y pautas de conducta social que tiene lugar en el seno de diversos grupos. Y por ello, se podría añadir, si es la sociedad la que educa, debe estar involucrada y participar de las decisiones que se adopten en materia de educación. Lograr implicar a la sociedad tomando en cuenta su opinión no supone garantizar el éxito ni reduce el riesgo, pero permite consensuar las decisiones y, en cierta forma, reducir el impacto social de los errores.

Esta implicación y apoyo social conlleva la necesaria participación de nuevos actores en la acción educativa, en especial de las familias y de los municipios. Como se señaló en un apartado anterior, si el contexto familiar es uno de los factores determinantes del progreso educativo, es imprescindible mejorar su formación y su nivel cultural. Por ello, lograr que las familias se acerquen a las nuevas tecnologías permitirá una mayor aproximación a la cultura de sus hijos y a su forma de aprender.

Por otro lado, el municipio puede convertirse en el marco principal que permita potenciar la coordinación de los distintos sectores relacio- nados con la educación, en especial aquellos situados en zonas rurales con menor acceso a la educación y a la cultura. Impulsar programas integrales que incorporen las TIC como herramientas de formación y trabajo puede ser una estrategia fundamental para lograr este propósito.

Estos presupuestos deben adelantarse en un espacio virtual de aprendizaje (EVA), esto es, "una aplicación informática diseñada para facilitar la comunicación pedagógica entre los participantes en un proceso educativo, sea este completamente a distancia, presencial, o de una naturaleza mixta que combine ambas modalidades en diversas proporciones" (Adell, Castellet y Pascual, 2004, p. 4, en Silva, 2011, p. 63), y que haga de estrategias pedagógicas tales como materiales educativos en formato digital (textos, imágenes, audio, simulaciones, etc.), debates en línea y la integración, contenidos relevantes de la red para posibilitar la participación de expertos o profesionales externos a través de foros interactivos. Silva (20011, p. 63) define el Eva así:

Un Entorno Virtual de Aprendizaje es un espacio diseñado con finalidades formativas: debe diferenciarse de un espacio web bien estructurado, pues éste no garantiza aprendizaje. El diseño debe nutrirse principalmente de las investigaciones relacionadas con la estructuración y representación de la información y cómo puede ser utilizada en actividades de aprendizaje e interacción.

Por esta razón y compartiendo el concepto de Silva (2011, pp. 75 y 76), es necesario que un modelo participante basado en TIC —EVA para la 
pedagogía constitucional - tenga en cuenta los siguientes presupuestos:

- El aprendizaje debe tener lugar en entornos auténticos del mundo real. La experiencia social y con objetos es el catalizador primario del conocimiento, puesto que proporciona la actividad sobre la cual opera la mente.

- El aprendizaje debe implicar negociación social y mediación. La interacción social proporciona el desarrollo de destrezas y conocimientos socialmente relevantes así como un mecanismo para las perturbaciones que pueden requerir adaptación individual.

- Los contenidos y destrezas deben ser relevantes para el estudiante. El conocimiento sirve a una función adaptativa, por lo tanto, debe ser relevante con respecto a la situación actual del individuo (significados, metas y objetivos, etc.). Esta relevancia conduce a un aumento de la motivación en la medida en que el sujeto comprende la necesidad de cierto conocimiento.

- Los contenidos y destrezas deben ser comprendidos dentro de la estructura de los conocimientos anteriores del aprendiz. Todo aprendizaje comienza con los conocimientos previos del individuo. Los errores son especialmente significativos para comprender las reglas y estructuras de los aprendices. Las nuevas experiencias de aprendizaje solo pueden asentarse en los conocimientos previos de los aprendices.

- Los estudiantes deben ser evaluados de manera formativa, de modo que esta información sirva para futuros aprendizajes. Las experiencias y actividades formativas deben basarse en los conocimientos previos, pero estos no son directamente observables, son solo inferibles de la actuación de los aprendices. La evaluación formativa es la manera de obtener dicha información, necesaria para diseñar las siguientes experiencias y actividades de aprendizaje.

- Los estudiantes deben ser estimulados a convertirse en aprendices autorregulados, automediados y autoconscientes. La metacognición es: a) conocimiento de la cognición (saber lo que uno sabe, saber lo que uno es capaz de hacer y saber qué hacer y cuándo) y b) regulación de la cognición (la tarea constante de planificar, monitorizar y evaluar el propio conocimiento y aprendizaje).

- Los profesores sirven prioritariamente de guías y facilitadores del aprendizaje, no de instructores. El papel del profesor en el proceso de aprendizaje es crear experiencias para los estudiantes que les conducirán a la adquisición de conocimientos. Su papel es motivar, proporcionar ejemplos, discutir, facilitar apoyo y desafiar, pero no intentar actuar como un conducto del conocimiento.

- Los profesores deben proporcionar múltiples perspectivas y representaciones de los contenidos. Experimentar múltiples perspectivas de un evento particular ofrece al estudiante los materiales necesarios para desarrollar múltiples representaciones de los hechos.

\section{CONCLUSIONES}

En la actualidad, las tensiones que vive el sistema educativo son un fiel reflejo de la compleja situación social existente en los países. La consolidación de sociedades profundamente desiguales, heterogéneas y multiculturales, conse- 
cuencia de los continuos flujos migratorios; la globalización de la economía y la revalorización de la educación como instrumento para el cambio han tenido un impacto directo en los sistemas formativos. En este nuevo contexto, caracterizado por el advenimiento del mundo virtual en contextos marcados hasta entonces por su fuerte presencialidad física, las TIC encierran una serie de impactos en la educación, entre los que se encuentran:

- La exigencia de nuevas destrezas, al momento de saber buscar y transmitir información, a través de las Tic, tanto de estudiantes como de docentes.

- La posibilidad de nuevos procesos de enseñanza y aprendizaje, para el aprovechamiento de las funcionalidades que ofrecen las tIc.

- La creciente demanda de un nuevo sistema educativo en el que se garantice la instrumentalización de las TIC al interior de estos espacios, como la formación holística de todo lo que ellas enmarcan para el proceso de acceso y construcción del conocimiento por parte de estudiantes y docentes (Said, 2009, p. 81)

En la medida que se asuman cada uno de estos impactos de las tıc en la educación se podrán lograr las funcionalidades potenciales que estas encierran al momento de fortalecer los contextos de enseñanza-aprendizaje. "Estos nuevos escenarios en los que se enmarca la educación ponen de manifiesto la necesidad de reorientar y llevar a cabo cambios sustanciales en el paradigma educativo, que permitan hacer frente a las nuevas demandas sociales" (Díaz, 2012, p.
155). ${ }^{20}$ Los métodos de enseñanza deben ser acordes con los nuevos usos que implica la introducción de la tecnología en la educación:

Conviene destacar que la escuela difícilmente puede seguir el ritmo frenético con que se está operando esta transformación. Aunque queden ya pocas personas y menos instituciones que todavía escriban a mano o con máquina mecánica o eléctrica, la escuela todavía sigue enseñando a escribir de modo analógico, con lápiz y sacapuntas, con todas las implicaciones que tiene: énfasis en cuestiones caligráficas y ortográficas, menos posibilidad de reformulación, etc. Indudablemente, este hecho debe resultar desmotivador para el aprendiz que tenga o no ordenador en su casa- ve que en el centro escolar siguen enseñando a escribir de una manera que ya nadie usa en la comunidad (Cassany, 1999, p. 96). [Cursivas añadidas].

El acceso y el uso estratégico de las tic permite promover el desarrollo económico, la reducción de la pobreza y la democratización (libertad de expresión, derechos a la educación e información, control político-ciudadano y defensa de los derechos humanos), por lo que el papel que estas juegan en una sociedad como la colombiana resulta fundamental siempre y cuando las TIC desempeñen un lugar central en la cooperación para el desarrollo de aquellas acciones orientadas al avance de la democracia.

20 "En la escuela, el docente organiza la actividad para la enseñanza y la lengua escrita. En cambio los eventos de lectura y escritura que surgen en la vida cotidiana se disponen con fines comunicativos y, por ello, son importantes contextos para la apropiación de los diversos usos de la lectura escrita. Es precisamente a través de la participación de este tipo de eventos donde el individuo aprende los usos no escolares de la lectura y la escritura. Como noción teórica, la participación se refiere al proceso de intervenir en actividades sociales, así como las relaciones que se establecen entre los diferentes actores" (Kalman 2003, p. 120). 
Por lo anterior, podría afirmarse que a mayor acceso a la educación no solo hay más desarrollo de capital humano y económico, ${ }^{21}$ sino la consolidación paulatina, pero sólida y eficaz de la democracia y, para el caso colombiano, del Estado social de derecho. Esta meta difícilmente se podría consolidar si se deja de lado el empleo de una herramienta tan útil como las TIC.

A pesar de las reticencias existentes a la hora de usar las TIC, se puede encontrar un modelo pedagógico que permita la relación entre el uso de la tecnología y el cuidado y desarrollo de los valores democráticos a través de este, pues, es posible afirmar que dentro de estos entornos virtuales de aprendizaje, "las tIc se pueden considerar potentes herramientas colaborativas, ya que permiten generar espacios adecuados para la interacción y el intercambio, favorecen la puesta en práctica de valores como la solidaridad y promueven nuevas estrategias de comunicación, de colaboración y de diálogo" (Díaz, 2012, p. 163).

La incorporación de las tic en la pedagogía constitucional no garantiza por sí sola la inclusión, la equidad social y la eficacia de los derechos

21 "Los niños de familias de bajos ingresos pueden beneficiarse del acceso a una enseñanza asistida por computadora que comprenda programas informáticos interactivos bien concebidos que propicien la adquisición de cualificaciones y de las competencias previstas en el plan de estudios. Un estudio a pequeña escala realizado en escuelas en zonas de bajos ingresos de Tel Aviv (Israel) mostró que los alumnos de quinto grado que utilizaban un programa de actividades didácticas interactivas asistidas por computadora, impartido mediante computadoras portátiles individuales, habían logrado mejoras en el aprendizaje mucho más importantes que los alumnos que recibían la enseñanza en un entorno tradicional. El programa informático especialmente diseñado, ajustado al plan de estudios nacional, permitió a los docentes proporcionar distintos materiales a los alumnos con diferentes niveles de rendimiento y dejarlos trabajar según sus propias capacidades (Rosen y Manny-Ikan, 2011)" (UNESCO, 2014, p. 501). fundamentales y los valores democráticos, razón por la cual el desafío será poder comunicar estos criterios a través de los nuevos medios, así como formar y enseñar otros valores que permitan a las futuras generaciones desenvolverse dentro de la cultura digital de una forma democrática, responsable y solidaria. Por esta razón, es necesario continuar en la creación -o reinvención- e implementación de modelos educativos que permitan explorar y explotar las potencialidades que estas nuevas herramientas ofrecen para lograr cambios sustanciales en la sociedad y en la educación, tal y como ocurriría con un modelo pedagógico dialogante con uso de las TIC.

\section{Referencias}

Arango, R. (2005). El concepto de derechos sociales fundamentales. Bogotá: Legis.

Bruguera, E. y Campás, J. (2007). El hipertexto y los blogs. Barcelona: voc.

Carbonell Sebarroja, J. (2005). El profesorado y la innovación educativa. En: P. Cañal de León, La Innovación educativa (págs. 11-26). Madrid: Ediciones Akal, S. A.

Cassany, D. (1999). Construir la escritura. Barcelona: Paidós.

Cifuentes, F. (2013). La lectura digital. Recuperado el 15 de febrero de 2013 de http:// www.elabedul.net/Articulos/la_lectura_digital.php . 
Colombo Villarrasa, C. (2007). e-Participación: las TIC al servicio de la innovación democrática. Barcelona: voc.

Contreras Jordán, O. R. (2000). La formación inicial y permanente del profesor de educación física. I. Ciudad Real: Ediciones de la Universidad de Castilla-La Mancha.

Corrales, R. (2003). Justicia constitucional en Bolivia: hacia el fortalecimiento del régimen democrático. Quito: Producciones Digitales Abya-Yala.

Corte Constitucional. Sentencia T-227 de cinco (5) de mayo 1997. M. P.: Alejandro Martínez Caballero.

Corte Constitucional. Sentencia SU-624 de veinticinco (25) de agosto de 1999. M. P.: Alejandro Martínez Caballero.

Corte Constitucional. Sentencia T-780 de 12 de octubre de 1999. M. P.: Álvaro Tafur Galvis.

Corte Constitucional. Sentencia T-179 de 24 de febrero de 2000. M. P.: Alejandro Martínez Caballero.

Corte Constitucional. Sentencia C-1109 de 24 de octubre de 2001. M. P.: Jaime Córdoba Triviño.

Corte Constitucional. Sentencia T-807 de 18 de septiembre de 2003. M. P.: Jaime Córdoba Triviño.
Corte Constitucional. Sentencia T-1227 de 28 de noviembre de 2005. M. P.: Jaime Araújo Rentería.

Corte Constitucional. Sentencia T-234 de seis (6) de marzo de 2008. M. P.: Clara Inés Vargas.

David Paul, A. y Foray, D. (s. f.). Una introducción a la economía y a la sociedad del saber. Recuperado el el 1 de marzo de 2013 de http:// www.oei.es/salactsi/david.pdf

De Antonio Gómez, A. (2001). Pedagogía constitucional: un análisis jurídico-político de la Constitución de 1991. Bogotá: Universidad Jorge Tadeo Lozano.

De Zubiría Samper, J. (2006). Los modelos pedagógicos: hacia una pedagogía dialogante. Bogotá: Editorial Magisterio.

Díaz, T. (2012). La función de las tıc en la transformación de la sociedad y de la educación. En R. Carneiro, J. C. Toscano y T. Díaz (Edits.), Los desafíos de las tic para el cambio educativo. Madrid: Organización de Estados Iberoamericanos (OEI) y Fundación Santillana.

Fuster, M. (2012). Concepción de la participación en entornos en línea: lecciones y retos para las experiencias de democracia digital. En I. Ramos Vielba y E. Campos Domínguez (Edits.), Ciudadanía en 3D, democracia digital deliberativa. Un análisis exploratorio. Madrid: Fundación Ideas. 
Gargallo López, B. y Suárez Rodríguez, M. I. (2003). La integración de las nuevas tecnologías en los centros: una nueva aproximación multivariada. Valencia: Centro de Investigación y Documentación Educativa (CIDE).

Gómez, B. I. (2002). El hipertexto como herramienta didáctica. En B. C. Barbosa Alonso, El oficio de investigar: educación y pedagogía frente a nuevos retos. Bogotá: Universidad Pedagógica Nacional.

Goñi Zabala, J. J. (2008). Talento, tecnología y tiempo. Los pilares de un progreso consciente para elegir un futuro. Madrid: Ediciones Díaz de Santos.

Häberle, P. (2003). El estado constitucional. (H. Fix-Fierro, Trad.). México: Universidad Nacional Autónoma de México.

Kalman, J. (2003). El acceso a la cultura escrita: la participación social y la apropiación de conocimientos en eventos cotidianos de lectura y escritura. Revista Mexicana de Investigación Educativa, VIII (17), 37-66.

Lamarca Lapuente, M. J. (s. f.). Lectura y escritura digitales. Recuperado el 15 de febrero de 2013 de http://artesadigital.blogspot. com/2009/01/lectura-y-escritura-digitales. html

Marchesi, A. y Díaz, T. (enero-marzo, 2009). Los desafíos de las Tic para el cambio educativo en Iberoamérica. Telos, (78).
Mochi, P. (2001). Nuevas tecnologías y democracia participativa: propuestas para desarrollar líneas de investigación. Recuperado el 2 de marzo de 2014 de http://www.citidep. pt/papers/pma/prud_gto01.html

Organización de las Naciones Unidas para la Educación la Ciencia y la Cultura. (2014). Enseñanza y aprendizaje: lograr la calidad para todos. París: Unesco.

Ortiz, O. (s. f.). Lectura y escritura en la era digital. Desafíos que la introducción de las TIC impone a la tarea de estimular el desarrollo del lenguaje en niños y jóvenes. Recuperado el 15 de febrero de 2013 de http://www.uib.es/ depart/gte/edutec-e/revelec17/ortiz_16a. htm.

Ortiz Ocaña, A. (2009). Pedagogía y docencia universitaria. Hacia una didáctica de la educación superior. Bogotá: Ediciones CEPEDID.

Landow, G. (2009). Hipertexto 3.0. Teoría crítica y los nuevos medios en la era de la globalización. Barcelona: Paidós.

Poca, A. (1991). La escritura: teoría y técnica de la transmisión. Barcelona: Montesinos Editor, S. A.

Rojano, M. (2006). 10 años de periodismo digital en Venezuela 1996-2006. Caracas: Universidad Católica Andrés Bello.

Said Hung, E. (2009). TIC y periodismo digital en el contexto escolar. En E. Hung (Ed.), La educación como escenario de oportunidades 
para el desarrollo de Barranquilla (págs. 7697). Barranquilla: Alcaldía de Barranquilla y Universidad del Norte.

Silva Quiroz, J. (2011). Diseño y moderación de entornos virtuales de aprendizaje (EVA). BarceIona: Editorial uoc.

Schmelkes, S. (s. f.). La interculturalidad en la educación básica. Recuperado el 12 de diciembre de 2013 de http://www.amdh.com. $\mathrm{mx} /$ ocpi/documentos/docs/6/16.pdf

Tedesco, A. B. (2003). Educación a distancia y nuevas tecnologías: la formación de docentes críticos. Revista Iberoamericana de Educación. Principal oEI, (33).

Trujillo García, S. (2008). La subjetividad: un argumento para implicar. Propuesta para una pedagogía de los afectos. Bogotá: Pontificia Universidad Javeriana.

Uprimny Yepes, R. (26 de enero de 2013). Democracia y TIC. Recuperado el 25 de febrero de 2013 de http://www.elespectador.com/ opinion/columna-399271-democracia-y-tic . 